\title{
Determining the Influence of Model Parameters on THE CHOOSING OF AN OPTIMAL Size RANGE OF THE PRODUCT "PiPe Clamp"
}

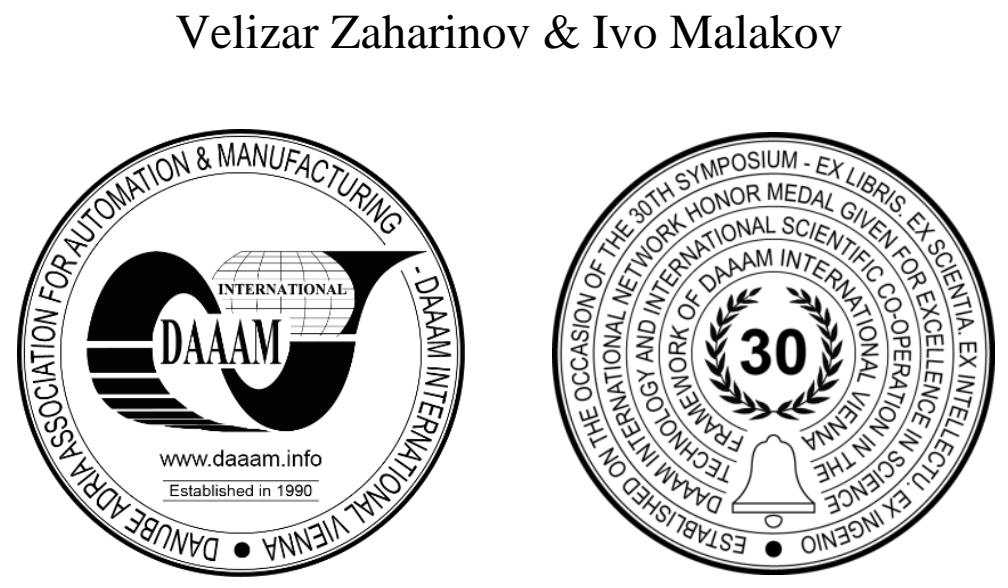

This Publication has to be referred as: Zaharinov, V[elizar] \& Malakov, I[vo] (2019). Determining the Influence of Model Parameters on the Choosing of an Optimal Size Range of the Product "Pipe Clamp", Proceedings of the 30th DAAAM International Symposium, pp.0324-0333, B. Katalinic (Ed.), Published by DAAAM International, ISBN 9783-902734-22-8, ISSN 1726-9679, Vienna, Austria DOI: $10.2507 / 30$ th.daaam.proceedings.043

\begin{abstract}
The paper presents the results from a study on the influence of some parameters of a developed mathematical model, on the solution of the problem for size range optimization of the product "Pipe clamp". The optimal solution is found using a known method and developed recurrent relations. For determining the influence of chosen model parameters, the optimization problem is solved for different values of the same while keeping the values of the other parameters constant. An assessment is made regarding the influence of the studied parameters on the optimal solution. The information obtained shows which are the most important model parameters, for which the most accurate data must be gathered. This would allow less resources to be spent for determining the values of the rest of the mathematical model's parameters. The presented study is one of the important stages of the design approach for developing optimal size ranges. The proposed approach can be used as a tool for the design of product family.
\end{abstract}

Keywords: size ranges; product family; optimization; pipe clamp; mathematical model; post-optimal analysis.

\section{Introduction}

A significant part of the mass produced products in mechanical engineering, electronics, electrical engineering, automotive industry, and other industry branches are produced in size (parametric) ranges, which are at the basis of the modular product families [5, 14, 19].

The choice of an optimal size range, predefines in great deal, the good economic results for the manufacturer, as well as for the users, of mass produced technical products from different industry branches [3], [4], [5], [9], [13], [18]. It is related to defining the elements of such a size range, that with minimum costs and/or maximum efficiency (profit) in the area of manufacturing and operation, completely satisfies given product demand regarding quantity [3], [6], [7], [8], [12]. Solving this problem is related to numerous difficulties [3], [7].

One of the main difficulties comes from the necessity for forecasting demand for products with different values of their main parameters, and building a functional dependency between a chosen optimality criterion/criteria and the influencing factors. Solving these problems is related to collecting and processing of a vast quantity of heterogeneous technical and 
economic information, referring to the connections of the designed size range with its environment throughout the different stages of the size range's lifecycle, and requires substantial expenditure of time, labour, and highly qualified specialists from different fields - marketing, design, manufacturing, operation, etc. These activities are carried out in the earliest design stages, which stages are characterized by uncertainty and incomplete information regarding some of the influencing factors, and uncertainty increases with increase in product complexity [6], [10], [11]. It is known, that the higher the degree of uncertainty of the initial information is, the lower is the quality and reliability of the decisions made, and the probability for error is higher. This leads to a pursuit for decreasing uncertainty, but to that end significant expense of time and labour is needed.

On the other hand, for companies it is particularly important to study different possible situations related to the change in demand of products, production volume, costs, manufacturing conditions, operation, etc.

All of this determines the necessity for studying the dependency between the optimal solution and the change in the problem's parameters (coefficients and elements of the objective function, demand, production volume, feasible application areas, etc.) [2], [17]. To that end, the optimization problem is solved while one or several parameters are changed in certain limits, and the rest of the parameters remain constant. The analysis of the obtained results will allow for [14], [15], [16]:

- studying the influence of the individual parameters of the mathematical model on the solution of the optimization problem, and determining the most important ones, for which the most accurate information must be obtained. This will allow for less resources to be spent when determining the values of the rest of the model's parameters;

- obtaining information regarding the behaviour of the problem's solution in different situations, related to change in some model's elements - demand, production volume, etc.;

- analysing the workings of the developed mathematical model, and estimating if it is properly built;

- modifying (calibrating) the mathematical model for the purpose of adequately reflecting the real conditions, etc.

Subject of examination is the optimal size range of the product "Pipe clamp" (Fig. 1), determined after solving the problem by means of a proposed approach [6], [7]. The product has a broad application in the construction industry when building pipelines and pipe installations (plumbing, heating, ventilation, sewer, etc.) in residential, industrial, office, public and other types of buildingsq as well as for building automation. Its main function is the fastening of pipes, through which different fluids flow, to walls, ceilings and other bases. Moreover, each clamp has a particular application range, i.e. it can be used for fastening of pipes with outside diameter that falls in the corresponding range. This product is particularly suitable for size range optimization, as it is produced in large series, and the appropriate reduction of the sizes' variety, and the related lowering of costs, would lead to a significant effect.

The aim of the paper is to show the results from a study on the influence of the change in some parameters of the model of the problem for choosing an optimal size range of the product "Pipe clamp" on its solution.

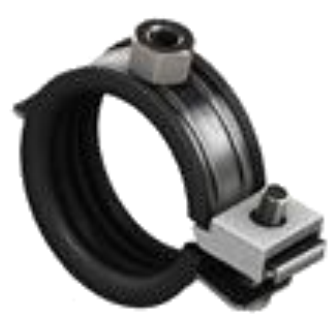

Fig. 1. Clamp for fixing of pipes with one screw

\section{Mathematical model}

The mathematical model of the problem for choosing an optimal size range has the form: for a given demand set $\bar{N}=$ $\left\{\bar{N}^{1}, \bar{N}^{2}, \ldots, \bar{N}^{l}, \ldots, \bar{N}^{\bar{L}}\right\}, l=1 \div \bar{L}$, of products $\bar{Z}=\left\{\bar{x}_{1}, \bar{x}_{2}, \ldots, \bar{x}_{l}, \ldots, \bar{x}_{\bar{L}}\right\}, l=1 \div \bar{L}$, and their allowable possibilities for satisfying the different demand types, i.e. the elements of the applicability matrix $\Phi_{\bar{L} \times \bar{L}}=\left\|\varphi_{m}^{p}\right\|_{\bar{L} \times \bar{L}}$, find $L^{*}, Z^{*}=$ $\left\{x_{l_{1}}^{*}, x_{l_{2}}^{*}, \ldots, x_{l_{j}}^{*}, \ldots, x_{l_{L^{*}}}^{*}\right\}, Z^{*} \subseteq \bar{Z}, j \in\{1,2, \ldots, \bar{L}\}, N^{*}=\left\{N^{* l_{1}}, N^{* l_{2}}, \ldots, N^{* l_{j}}, \ldots, N^{* l_{L^{*}}}\right\}, L^{*} \leq \bar{L}$, for which a chosen effectiveness (optimality) criterion has a minimum value:

$$
\begin{aligned}
& \operatorname{minR}\left(L, \bar{x}_{1}, \ldots, \bar{x}_{l}, \ldots, \bar{x}_{\bar{L}}, \bar{N}^{1}, \ldots, \bar{N}^{l}, \ldots, \bar{N}^{L}, \Phi_{\bar{L} \times \bar{L}}\right)=\sum_{j=1}^{L} G\left\{x_{l_{j}}, N^{l_{j}}\left(\varphi_{m}^{p}, N^{p}\right)\right\}= \\
& =\sum_{j=1}^{L} \operatorname{TS}\left(x_{l_{j}}\right) N^{l_{j}}\left(\varphi_{m}^{p}, N^{p}\right)\left(\frac{N_{T S}}{{ }_{N} l_{j}}\right)^{v_{1}}+\sum_{j=1}^{L} T P\left(x_{l_{j}}\right) N^{l_{j}}\left(\varphi_{m}^{p}, N^{p}\right), L=1 \div \bar{L}
\end{aligned}
$$

for the following conditions: 
$\sum_{j=1}^{L} N^{l_{j}}=\sum_{j=1}^{L^{*}} N^{* l_{j}}=\sum_{l=1}^{\bar{L}} \bar{N}^{l}=N_{0}$,

$x_{l_{L}}=x_{l_{L^{*}}}^{*}=\bar{x}_{\bar{L}}$

$x_{l_{j}} \in \bar{Z}=\left\{\bar{x}_{1}, \bar{x}_{2}, \ldots, \bar{x}_{l}, \ldots, \bar{x}_{m}, \ldots, \bar{x}_{\bar{L}}\right\}, \forall j=1 \div \bar{L}$,

where $R$ is total costs for all elements in the size range; TS $\left(x_{l_{j}}\right)$ - the production costs for the $l_{j}$-th size; $\bar{L}$ - the number of elements of the initial size range $\bar{Z}=\left\{\bar{x}_{1}, \bar{x}_{2}, \ldots, \bar{x}_{l}, \ldots, \bar{x}_{m}, \ldots, \bar{x}_{\bar{L}}\right\}$, determined after demand research, $\operatorname{dim} \bar{Z}=\bar{L} ; L-$ the number of elements in the currently analysed size range $Z=\left\{x_{l_{1}}, x_{l_{2}}, \ldots, x_{l_{j}}, \ldots, x_{l_{L}}\right\}, j \in\{1,2, \ldots, \bar{L}\}$. There exists a simple representation between the elements of the current and initial size range, whereby to each element $x_{l_{j}}$ corresponds an element $\bar{x}_{m}$. The elements of the current size ranges are a combination of $L, L=1 \div \bar{L}$, elements of $\bar{L}$ number of possible elements of the initial size range, taking into account their allowable application ranges; $L^{*}$ - the number of elements in the optimal size range $Z^{*}=\left\{z^{* l_{1}}, z^{* l_{2}}, \ldots, z^{* l_{j}}, \ldots, z^{* L_{L^{*}}}\right\}, j=1 \div L^{*}, L^{*} \leq \bar{L} ; \Phi_{\bar{L} \times \bar{L}}=\left\|\varphi_{m}^{p}\right\|_{\bar{L} \times \bar{L}}$-applicability matrix, which elements give information about the possible allowable application ranges for the products in the initial size range $\bar{Z}=\left\{\bar{x}_{1}, \bar{x}_{2}, \ldots, \bar{x}_{\bar{L}}\right\}$ for satisfying the separate demand types $\bar{N}=\left\{\bar{N}^{1}, \bar{N}^{2}, \ldots, \bar{N}^{\bar{L}}\right\}$, where $\varphi_{m}^{p}=1$, if the product of $m$-th type, $m=1 \div \bar{L}$, can satisfy the demand $\bar{N}^{p}$ of product $\bar{x}_{p}, p=1 \div \bar{L}$, and $\varphi_{m}^{p}=0$ otherwise; $N^{l_{j}}\left(\varphi_{m}^{p}, N^{p}\right)$ - the demand of product $x_{l_{j}}$ element of the currently analysed size range $Z=\left\{x_{l_{1}}, x_{l_{2}}, \ldots, x_{l_{j}}, \ldots, x_{l_{L}}\right\}$, whose index $l_{j}$ corresponds to the index $m$ of product $\bar{x}_{m} \in \bar{Z}$, element of the initial size range, where $x_{l_{j}}=\bar{x}_{m}$, and $N^{l_{j}}\left(\varphi_{m}^{p}, N^{p}\right)=\sum_{p=l_{j-1}}^{l_{j}} \varphi_{l_{j}}^{p} N^{p} ; N_{0}$ - total production quantity of all elements in the size range; $N^{l_{j}}$ - the quantity of $l_{j}$-th product size, $N^{l_{j}} \in N=\left\{N^{l_{1}}, N^{l_{2}}, \ldots, N^{l_{L}}\right\}$, where $N$ is the demand set for the products of the current size range; $v_{1}$ - the coefficient, describing the intensity of change in costs in relation to the change in the production quantity, taking into account the "learning rate"; $N_{T S}$ - the coefficient, accounting for the production scale factor.

Condition (2) means, that all analysed size ranges, including the optimal, must satisfy all demand in terms of quantity, condition (3) means, that every size range, including the optimal, must include the element from the initial size range with the maximum value of its main parameter $\bar{x}_{\bar{L}}$, and condition (4), that the elements of all size ranges are chosen from the set of elements of the initial size range, determined after demand research.

The demand for each clamp size included in the initial size range $\bar{Z}=\left\{\bar{x}_{1}, \bar{x}_{2}, \ldots, \bar{x}_{l}, \ldots, \bar{x}_{\bar{L}}\right\}$, is determined after a market research, i.e. the elements of the set $\bar{N}=\left\{\bar{N}^{1}, \bar{N}^{2}, \ldots, \bar{N}^{l}, \ldots, \bar{N}^{\bar{L}}\right\}, l=1 \div \bar{L}$, where $\bar{N}^{l}$ is the quantity of the required products of size $\bar{x}_{l}$. The obtained results are shown in Fig. 2. The product's main parameter values are input along the abscissa - the outer diameter of the fastened pipe, and along the ordinate - the corresponding quantity.

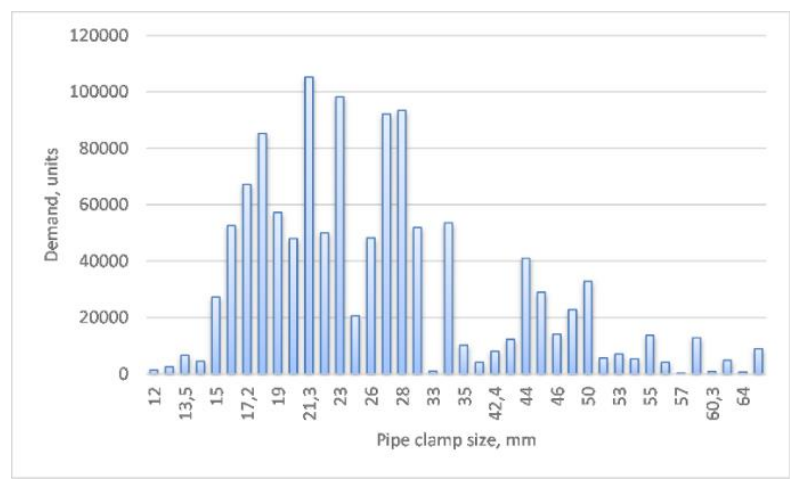

Fig. 2. Product demand from market research

\section{Solving the problem for choosing an optimal size range}

For choosing an optimal size range it is necessary to determine the functional relationship between the components of the optimality criterion $R$, and the influencing factors. To that end, an analysis of the production is carried out including production and operational costs data for the product "Pipe clamp". The software product "STATGRAPHICS" is used for data processing.

For determining the total costs the following dependency is obtained:

$$
R=\sum_{j=1}^{L} N^{l_{j}} \sqrt{0,0941207297+0,0000169074279 x^{l_{j}}}\left(\frac{50000}{N^{l_{j}}}\right)^{0,18}+\sum_{j=1}^{L} \frac{1,6 N^{l_{j}}}{2,45701992-0,0150975731 x^{l_{j}}}
$$

The formulated problem (1), (2), (3), and (4) for choosing an optimal size range belongs to the class of problems of the discrete programming. By its nature, it refers to distribution problems, but differs from them by the presence of 
variable number of arguments, and variable values of the arguments, which complicates its solution. Additionally, the problem characterizes with large number of possible size ranges, that have to be analysed [7].

This number, without taking into account the allowable application ranges of the discussed products, is determined from the expression $\sum_{k=1}^{\bar{L}-1} C_{\bar{L}-1}^{k}=2^{\bar{L}-1}-1$, where $k$ is the number of elements in the size range formed from the elements of the initial size range with $\bar{L}$ elements. For $\bar{L}=40$ it is necessary to consider $2^{39}-1=5,4975581.10^{11}$ different size ranges. This leads to a significant number of calculation procedures, and necessitate the use of a method for directed search of the optimal solution.

Furthermore, the method used, must allow for respecting the application ranges of each product in the size range. This lowers the number of analysed variants, but complicates the finding of solution.

According to a number of researchers [3], [8], [14], one of the efficient methods for directed search for solving the problem in question is the dynamic programming method [1]. The principal advantage of the method is good adaptability to solving discrete optimization problems, while its application is not influenced by the type of objective function. The method is based on the optimality principle of Bellman, stating: „The optimal strategy has a property such that no matter what is the initial state of the system in question, and the first stage solution, the following solutions (the solutions of the separate stages) must constitute an optimal strategy with respect to the state obtained as a result from the first solution “.

On the basis of this principle the following recurrent dependencies for determining the total costs are obtained:

- for $l=1, m=l \div \bar{L}$,

$$
R_{m}^{l}=\frac{1}{\prod_{p=1}^{m} \varphi_{m}^{p}} G\left(\bar{x}_{m}, \sum_{p=1}^{m} N^{p}\right)=\frac{1}{\prod_{p=1}^{m} \varphi_{m}^{p}}\left[\operatorname{TS}\left(\bar{x}_{m}\right) \sum_{p=1}^{m} N^{p}\left(\frac{N_{T S}}{\sum_{p=1}^{m} N^{p}}\right)^{v_{1}}+\operatorname{TP}\left(\bar{x}_{m}\right) \sum_{p=1}^{m} N^{p}\right]
$$

- for $l=2 \div \bar{L}, m=l \div \bar{L}, m^{\prime}=(l-1) \div(m-1)$,

$$
\begin{aligned}
R_{m}^{l} & =\min \left\{R_{m^{\prime}}^{l-1}+\frac{1}{\prod_{p=m^{\prime}+1}^{m} \varphi_{m}^{p}} G\left(\bar{x}_{m}, \sum_{p=m^{\prime}+1}^{m} N^{p}\right)\right\}= \\
& =\min \left\{R_{m^{\prime}}^{l-1}+\frac{1}{\prod_{p=m^{\prime}+1}^{m} \varphi_{m}^{p}}\left[\operatorname{TS}\left(\bar{x}_{m}\right) \sum_{p=m^{\prime}+1}^{m} N^{p}\left(\frac{N_{T S}}{\sum_{p=m^{\prime}+1}^{m} N^{p}}\right)^{v_{1}}+T P\left(\bar{x}_{m}\right) \sum_{p=m^{\prime}+1}^{m} N^{p}\right]\right\},
\end{aligned}
$$

where $R_{m}^{l}$ is the minimum (optimal) objective function value for satisfying demand for products with main parameter value in the interval $\left(0, \bar{x}_{m}\right], m=1 \div \bar{M}$, with a number of $l$ sizes.

The problem (1) - (4) is solved with the aid of a developed algorithm and an application software.

The results are shown in Tab. 1 , where $R^{*}$ are the minimum (optimal) total costs, EUR; $L^{*}$ - - the number of elements in the optimal size range; $R_{\bar{L}}^{\bar{L}}$ - - the total costs of the size range including all possible sizes, i.e. of the initial size range, EUR.

The data for the chosen optimal size range are shown in Tab. 2 . The size range includes $L^{*}=9$ sizes.

\begin{tabular}{|c|c|c|c|c|}
\hline Indicators & $\boldsymbol{R}^{*}$ & $\boldsymbol{L}^{*}$ & $\boldsymbol{R}_{\bar{L}}^{\bar{L}}$ & $\frac{\boldsymbol{R}_{\bar{L}}^{\bar{L}}-\boldsymbol{R}^{*}}{\boldsymbol{R}_{\bar{L}}^{\bar{L}}}$ \\
\hline Optimal size range & 1289080,52 & 9 & 1360835,79 & $5,3 \%$ \\
\hline
\end{tabular}

Table 1. Results from solving the problem

\begin{tabular}{|c|c|c|c|c|c|c|c|c|c|}
\hline $\mathbf{N}$ & $\mathbf{1}$ & $\mathbf{2}$ & $\mathbf{3}$ & $\mathbf{4}$ & $\mathbf{5}$ & $\mathbf{6}$ & $\mathbf{7}$ & $\mathbf{8}$ & $\mathbf{9}$ \\
\hline $\begin{array}{c}\text { Size } x_{l_{j}}^{*} \in X^{*}, \\
j=1 \div 9\end{array}$ & $x_{l_{1}}^{*}$ & $x_{l_{2}}^{*}$ & $x_{l_{3}}^{*}$ & $x_{l_{4}}^{*}$ & $x_{l_{5}}^{*}$ & $x_{l_{6}}^{*}$ & $x_{l_{7}}^{*}$ & $x_{l_{8}}^{*}$ & $x_{l_{9}}^{*}$ \\
\hline $\begin{array}{c}\text { Size } \bar{x}_{m} \in \bar{X} \\
l \in\{1 \div \bar{L}\}\end{array}$ & $\bar{x}_{5}=15$ & $\bar{x}_{9}=19$ & $\bar{x}_{13}=23$ & $\bar{x}_{17}=28$ & $\bar{x}_{21}=35$ & $\bar{x}_{27}=46$ & $\bar{x}_{30}=51$ & $\bar{x}_{36}=58$ & $\bar{x}_{40}=65$ \\
\hline $\begin{array}{c}\text { Application } \\
\text { range }\end{array}$ & $12-15$ & $16-19$ & $20-23$ & $25-28$ & $28-35$ & $40-46$ & $45-51$ & $53-58$ & $57-65$ \\
\hline
\end{tabular}

Table 2. Optimal size range

The production quantities of each element of the optimal size range (1), and the elements of the initial size range (2) are shown in Fig. 3. The total costs curve, determined in the process of solving the problem, is shown in Fig. 4.

The found optimal size range of the product "Pipe clamp" is characterized by:

- reduction in the number of sizes from 40 to 9 , i.e. with $77,5 \%$; 
- reduction in the total costs in comparison to the size range including all possible sizes with 71755,27 EUR, i.e. with $5,3 \%$;

- reduction in the total costs in comparison to the size range including all possible sizes with 82 091,21 EUR, i.e. with $26 \%$, while incurring loss to the user of only 10336,43 EUR, i.e. of only $1 \%$ (Tab. 3 ).

As it can be seen from Fig. 4, there are a number of suboptimal solutions with values close to the optimum. These solutions (Tab. 4) can be provided to the decision maker for further analysis. In this way, when choosing an optimal size range, additional considerations can be taken into account that are not included in the mathematical model.

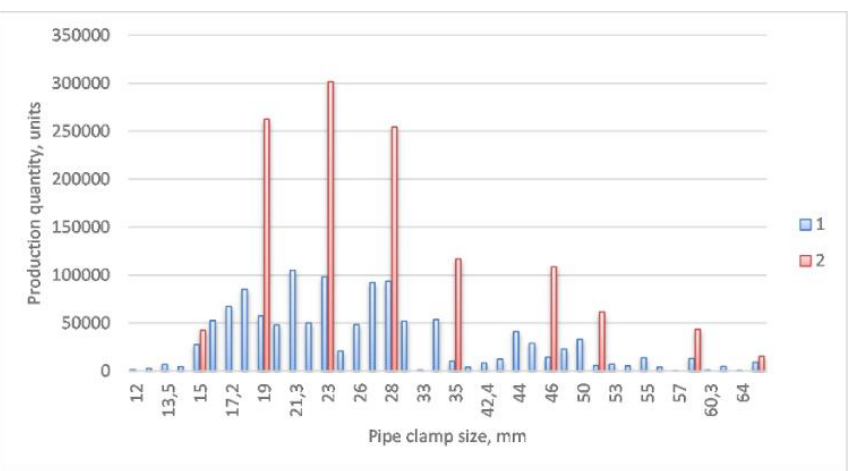

Fig. 3. Production quantity of the elements of the optimal size range (1), and the initial size range (2)

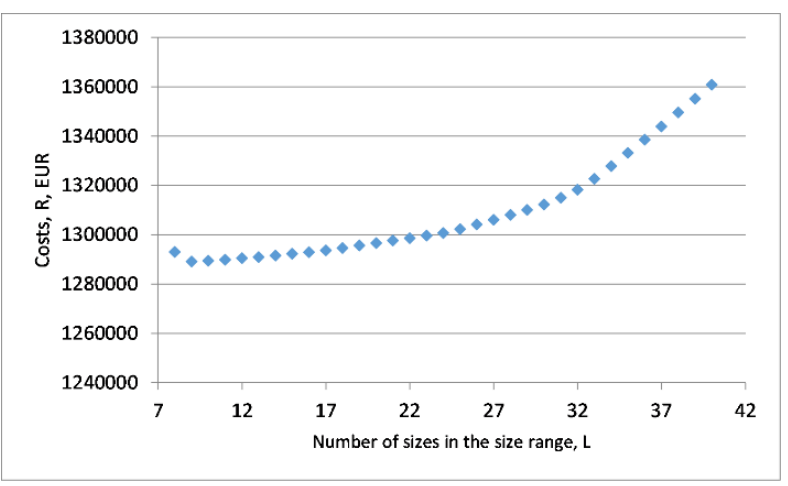

Fig. 4. Change in the total costs

\begin{tabular}{|c|c|c|}
\hline & $\boldsymbol{R}_{\overline{\boldsymbol{L}}}^{\overline{\boldsymbol{L}}}$ & $\boldsymbol{R}^{*}$ \\
\hline Manufacturer & 404580,42 & 322489,22 \\
\hline User & 956255,37 & 966591,80 \\
\hline
\end{tabular}

Table 3. Production and operational costs

\begin{tabular}{|c|c|c|c|c|c|c|c|}
\hline $\mathbf{N}$ & 1 & 2 & 3 & 4 & 5 & 6 & 7 \\
\hline$L$ & 8 & 10 & 11 & 12 & 13 & 14 & 15 \\
\hline$R$ & 1289085,02 & 1289400,65 & 1289825,35 & 290477,94 & 1290902,64 & 1291557,60 & 1292252,53 \\
\hline$\frac{R-R^{*}}{R_{\bar{L}}^{\bar{L}}-R^{*}} \cdot 100 \%$ & 0,006 & 0,446 & 1,038 & 1,948 & 2,539 & 3,452 & 4,421 \\
\hline$x_{l_{j}} \in X$ & $\begin{array}{c}16 ; 22 ; 26,9 \\
35 ; 46 ; 51 ; 58 \\
65\end{array}$ & $\begin{array}{c}15 ; 19 ; 23 \\
28 ; 35 ; 46 ; \\
51 ; 58 ; 60,3 \\
65\end{array}$ & $\begin{array}{c}12 ; 15 ; 19 ; \\
23 ; 28 ; 35 ; \\
46 ; 51 ; 58 \\
60,3 ; 65\end{array}$ & $\begin{array}{c}15 ; 19 ; 23 \\
28 ; 35 ; 46 ; \\
51 ; 58 ; 60,3 \\
63,5 ; 64 ; 65\end{array}$ & $\begin{array}{c}12 ; 15 ; 19 ; \\
23 ; 28 ; 35 ; \\
46 ; 51 ; 58 ; \\
60,3 ; 63,5 ; \\
64 ; 65 \\
\end{array}$ & $\begin{array}{c}12 ; 13 ; 15 ; \\
19 ; 23 ; 28 ; \\
35 ; 46 ; 51 ; \\
58 ; 60,3 ; \\
63,5 ; 64 ; 65 \\
\end{array}$ & $\begin{array}{r}12 ; 15 ; 19 ; \\
23 ; 28 ; 35 ; \\
46 ; 55 ; 56 ; \\
57 ; 58 ; 60,3 ; \\
63,5 ; 64 ; 65 \\
\end{array}$ \\
\hline
\end{tabular}

Table 4. Suboptimal solutions with difference from the optimal solution relative to $R_{\bar{L}}^{\bar{L}}-R^{*}$ less than or equal to $5 \%$

\section{Determining the influence of the model parameters on the problem solution}

The main goal is to determine the influence of independent components and parameters, included in the optimization problem's model, on its solution and to determine the most important once, for which the most accurate information must be obtained.

To that end, numerical experiments are carried out, which consist of solving the problem (1) - (4) for different values of the main coefficients and components included in the mathematical model.

The study consists of the following experiments:

A. Changing the demand function set $\bar{N}=\left\{\bar{N}^{1}, \bar{N}^{2}, \ldots, \bar{N}^{l}, \ldots, \bar{N}^{\bar{L}}\right\}$ while keeping the total production quantity;

B. Changing the quantity of production $N_{0}$;

C. Changing the application ranges of the separate elements of the initial size range, given by means of the applicability matrix $\Phi_{\bar{L} \times \bar{L}}=\left\|\varphi_{m}^{p}\right\|_{\bar{L} \times \bar{L}}$;

D. Changing the component $T S\left(x_{l_{j}}\right)$, which takes into account the production costs;

E. Changing the component $T P\left(x_{l_{j}}\right)$, which takes into account the operational costs. 


\subsection{Changing the demand function}

Problem (1) - (4) is solved for different demand functions as follows: experiment A1 - demand shown on Fig. 5, A2 - demand shown on Fig. 2 (initial problem), and A3 - demand shown on Fig. 6. For these experiments the overall production quantity is not changing, i.e. the sum of the demands for the separate sizes for each experiment has the same value. The solutions found are shown in Tab. 5.

In Fig. 7 a graphical representation is given of the total costs versus the number of sizes for different demand functions. It can be seen, that for different product demand distributions, the curves representing the total costs function, change shape significantly and have minimum for different number of sizes and different sizes values. Therefore, the deviation of the demand distribution from the real one, leads to a significantly different problem solutions. Because of this, for obtaining reliable optimization results, it is necessary to carefully and comprehensively gather customer orders data, i.e. market research, and to correctly determine the demand function.

\begin{tabular}{|c|c|c|c|}
\hline Experiment & A1 & A2 & A3 \\
\hline$L^{*}$ & 8 & 9 & 10 \\
\hline$R^{*}$ & 1418667,37 & 1289080,52 & 1410760,54 \\
\hline$R_{\bar{L}}^{\bar{L}}$ & 1499866,47 & 1360835,79 & 1493935,32 \\
\hline$x_{l_{j}}^{*} \in X^{*}$ & \multirow{2}{*}{$16 ; 22 ; 26,9 ; 35 ; 43 ; 50 ; 57 ; 65$} & \multirow{2}{*}{$15 ; 19 ; 23 ; 28 ; 35 ; 46 ; 51 ; 58 ; 65$} & $16 ; 21,3 ; 26 ; 26,9 ; 33,7 ; 35 ; 45 ; 50 ; 57 ;$ \\
\hline
\end{tabular}

Table 5. Results from solving the problem with different demand functions

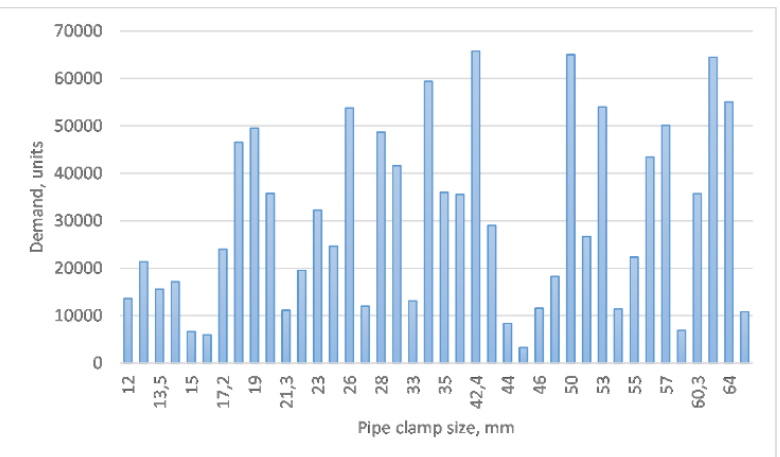

Fig. 5. Demand function for A1

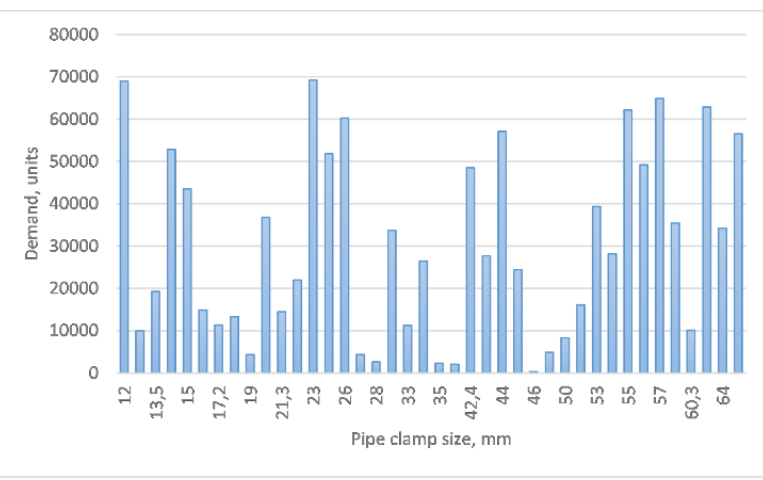

Fig. 6. Demand function for A3

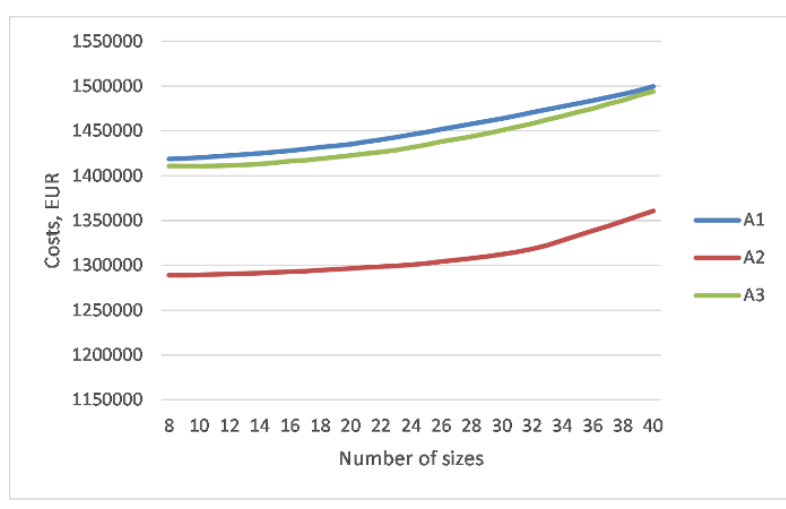

Fig. 7. Change in total costs for different demand functions

\subsection{Changing the production quantity}

Problem (1) - (4) is solved for different production quantities as follows: B0 - production quantity of the initial problem; B1 - doubling the production quantity; B2 - tripling the production quantity; B3 - quadrupling the production quantity; B4 - halving the production quantity; B5 - lowering three times the production quantity; B6 - lowering four times the production quantity. For these experiments the demand distribution do not change. The found solutions are shown in Tab. 6.

The following results are obtained for the total costs $R^{*}$ (Fig. 8): 
- Doubling, tripling, and quadrupling the production quantity leads to increase in the total costs accordingly with $94 \%$, $187 \%$, and $278 \%$ with respect to the total costs for the optimal size range of the initial problem;

- Halving, lowering three, and four times the production quantity leads to lowering of the total costs accordingly with $48 \%, 65 \%$, and $73 \%$ with respect to the total costs for the optimal size range of the initial problem.

\begin{tabular}{|c|c|c|c|c|c|c|c|}
\hline Experiment & B0 & B1 & B2 & B3 & B4 & B5 & B6 \\
\hline$L^{*}$ & 9 & 9 & 9 & 9 & 8 & 8 & 8 \\
\hline$R^{*}$ & 1289080,52 & 2502507,03 & 3693653,55 & 4871454,03 & 665510,08 & 452692,40 & 344625,44 \\
\hline$R_{\bar{L}}^{\bar{L}}$ & 1360835,79 & 2626759,44 & 3864731,60 & 5085960,42 & 707287,11 & 483083,06 & 368856,15 \\
\hline$x_{l_{j}}^{*} \in X^{*}$ & $\begin{array}{c}15 ; 19 ; 23 \\
28 ; 35 ; 46 ; \\
51 ; 58 ; 65\end{array}$ & $\begin{array}{c}15 ; 19 ; 23 ; \\
28 ; 35 ; 46 ; \\
51 ; 58 ; 65\end{array}$ & $\begin{array}{c}15 ; 19 ; 23 \\
28 ; 35 ; 46 ; \\
51 ; 58 ; 65\end{array}$ & $\begin{array}{c}15 ; 19 ; 23 \\
28 ; 35 ; 46 ; \\
51 ; 58 ; 65\end{array}$ & $\begin{array}{c}16 ; 22 ; \\
26,9 ; 35 ; \\
46 ; 51 ; 58 ; \\
65\end{array}$ & $\begin{array}{c}16 ; 22 ; \\
26,9 ; 35 ; \\
46 ; 51 ; 58 ; \\
65\end{array}$ & $\begin{array}{c}16 ; 22 ; \\
26,9 ; 35 ; \\
46 ; 51 ; 58 ; \\
65\end{array}$ \\
\hline
\end{tabular}

Table 6. Results from solving the problem with different production quantities

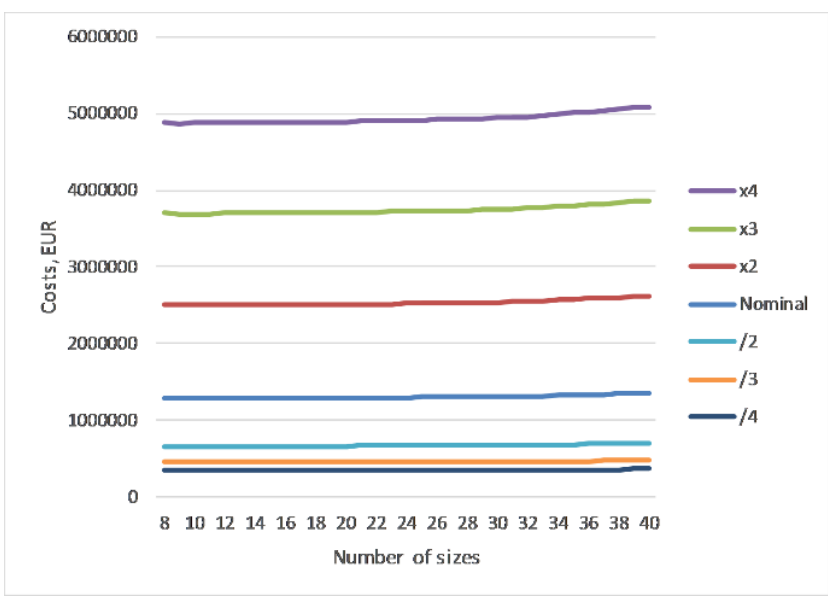

Fig. 8. Change in total costs for different production quantities

In addition, the number of sizes and their main parameter values are not changing in the optimal size range when increasing the production quantity. Lowering the production quantity, leads to a certain lowering of the number of sizes in the optimal size range. It can be observed that for a unidirectional change in the production quantity (increase or decrease) the values of the main parameter of the elements included in the optimal size range do not change, same elements when increasing - experiments B1, B2, and B3, and same elements when decreasing - experiments B4, B5, and B6.

\subsection{Changing the application ranges of the separate elements of the initial size range}

Problem (1) - (4) is solved for different application ranges of the separate elements of the initial size range. For the initial problem the sizes can be divided in two groups - the first group with application range of $4 \mathrm{~mm}$, and the second group - of $6 \mathrm{~mm}$. The study of the optimal solution for changes in the application range is done by changing the grouping. The different groupings for the experiments that took place are shown in Fig. 9. Horizontally, in the lower portion of the figure, the sizes are designated with $\bar{x}_{l}, l=1 \div \bar{L}$, and vertically, to the left, - the experiments. The application ranges are colour coded fields, and the code values are written in the field. The values designate the clamping range of the corresponding clamp size. For example for experiment $\mathrm{C} 1$ the size $\bar{x}_{10}$ is designated with $x_{10}$, and it has an application range of $4 \mathrm{~mm}$.

The experiments' results are shown in Tab. 7. The experiment with the initial problem is denoted C0.

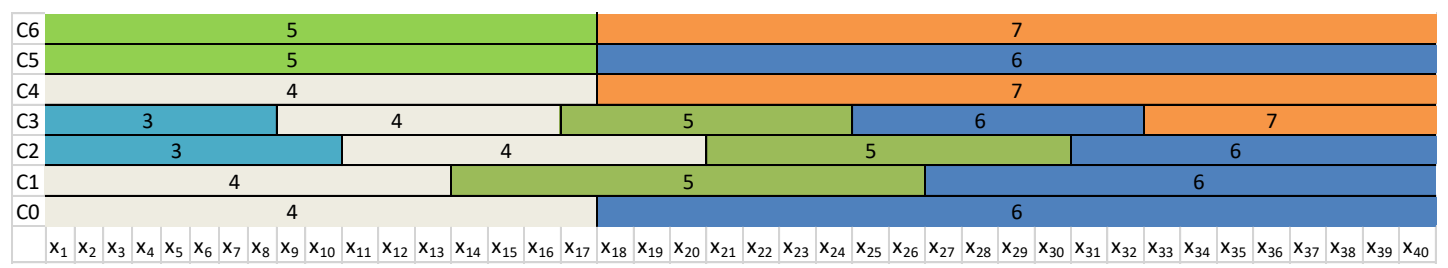

Fig. 9. Changing application ranges 
The results show, that for the so made changes to the application ranges, the total costs value for the different experiments barely changes - the biggest difference is between $\mathrm{C} 0$ and $\mathrm{C} 6$, and equals to $0,4 \%$. Even when neglecting design limitations (experiment $\mathrm{C} 7$ ) the difference is $1,3 \%$. The total costs for the size range including all elements do not change. On the other hand, the values and number of elements included in the optimal solution, depend significantly on the application ranges.

\begin{tabular}{|c|c|c|c|c|c|c|c|c|}
\hline Exp. & $\mathrm{CO}$ & C1 & $\mathrm{C2}$ & C3 & $\mathrm{C4}$ & $\mathrm{C5}$ & C6 & C7 \\
\hline$L^{*}$ & 9 & 9 & 9 & 9 & 9 & 8 & 8 & 5 \\
\hline$R^{*}$ & 1289080,52 & 1285945,99 & 1286536,73 & 1286373,92 & 1285839,49 & 1283655,32 & 1283548,82 & 1273032,09 \\
\hline $\begin{array}{l}x_{l_{j}}^{*} \\
\in X^{*}\end{array}$ & $\begin{array}{c}15 ; 19 ; \\
23 ; 28 ; \\
35 ; 46 ; \\
51 ; 58 ; 65\end{array}$ & $\begin{array}{l}13,5 ; 18 ; \\
23 ; 28 ; 35 \\
46 ; 51 ; 58 \\
\quad 65\end{array}$ & $\begin{array}{c}14 ; 18 ; \\
23 ; 28 ; \\
35 ; 45 ; \\
51 ; 58 \\
\quad 65\end{array}$ & $\begin{array}{c}14 ; 18 ; 23 \\
28 ; 35 ; 45 \\
50 ; 58 ; 65\end{array}$ & $\begin{array}{c}13,5 ; 18 \\
23 ; 28 ; 35 \\
45 ; 50 ; 58 \\
\quad 65\end{array}$ & $\begin{array}{c}17,2 ; 23 ; \\
28 ; 35 ; 46 ; \\
51 ; 58 ; 65\end{array}$ & $\begin{array}{c}17,2 ; 23 ; \\
28 ; 35 ; 45 ; \\
50 ; 58 ; 65\end{array}$ & $\begin{array}{c}28 ; 35 ; 50 \\
\quad 58 ; 65\end{array}$ \\
\hline
\end{tabular}

Table 7. Results from solving the problem with different application ranges

\subsection{Changing the production costs of the product}

The sensitivity of the optimal solutions is studied regarding changes in the component $T S\left(x_{l_{j}}\right)$ representing the production costs. The experiment is conducted for the following cases: D0 - initial problem; D1 - multiplying the production costs by 1,5; D2 - multiplying the production costs by 1,8; D 3 - multiplying the production costs by 2 . The found solutions are shown in Tab. 8.

\begin{tabular}{|c|c|c|c|c|}
\hline Experiment & D0 & D1 & D2 & D3 \\
\hline$L^{*}$ & 9 & 8 & 8 & 8 \\
\hline$R^{*}$ & 1289080,52 & 1446862,97 & 1541282,34 & 1604135,63 \\
\hline$R_{\bar{L}}^{\bar{L}}$ & 1360835,79 & 1563126,00 & 1684500,13 & 1765416,21 \\
\hline \multirow{3}{*}{$x_{l_{j}}^{*} \in X^{*}$} & $15 ; 19 ; 23 ;$ & $16 ; 22 ; 26,9 ;$ & $16 ; 22 ; 26,9 ;$ & $16 ; 22 ; 26,9 ;$ \\
& $28 ; 35 ; 46 ;$ & $35 ; 46 ; 55 ;$ & $35 ; 46 ; 55 ;$ & $35 ; 46 ; 55 ;$ \\
& $51 ; 58 ; 65$ & $58 ; 65$ & $58 ; 65$ & $57 ; 65$ \\
\hline
\end{tabular}

Table 8. Results from solving the problem with different production costs

Multiplying by $1,5,1,8,2$ the production costs, leads to increase in the total costs accordingly with $12 \%, 20 \%$, and $24 \%$ with respect to the total costs for the optimal size range of the initial problem (Fig. 10). The optimal number of sizes also changes. From 9 for the production costs of the initial problem, the optimal number of sizes changes to 8 when the production costs rise in the following experiments.

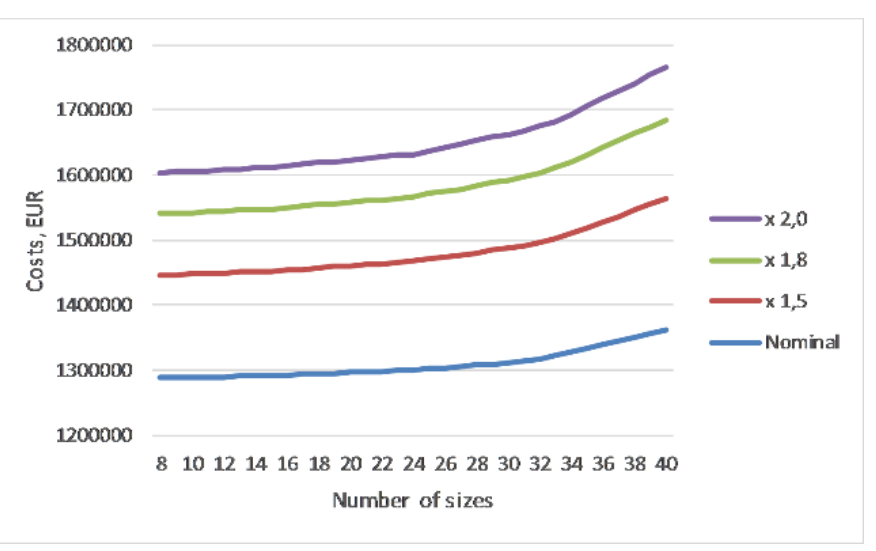

Fig. 10. Change in the total costs for change in the production costs

Raising the production costs also changes the elements included in the optimal solution in comparison to the initial problem D0. Nevertheless, there is a particular stability of the optimal solutions regarding the included elements.

As a result of the study of the production costs' influence on the optimal solution it can be stated that their increase leads to decrease in the number of sizes in the optimal size range. This shows that the mathematical model takes into account the manufacturer's wish for lowering the production costs by lowering the number of sizes in the size range. 


\subsection{Changing the operational costs}

The sensitivity of the optimal solutions is studied regarding changes in the component $T P\left(x_{l_{j}}\right)$ representing the operational costs. The experiment is conducted for the following cases: E0 - initial problem; E1 - multiplying the operational costs by 1,5; E2 - multiplying the operational costs by 1,8; E3 - multiplying the operational costs by 2 . The found solutions are shown in Tab. 9.

The total costs for the optimal size range increase with $38 \%$ when multiplying the operational costs by 1,5 . When the latter are multiplied by 1,8 the total costs increase with $60 \%$, and when multiplied by 2 - with $75 \%$ (Fig. 11).

The optimal number of sizes stays constant until doubling the operational costs. The elements included in the optimal size range change slightly between the experiments with the exception of E3.

The increase in operational costs leads to increase in the number of sizes in the optimal size range. This shows that the mathematical model takes into account the wish of the user to decrease operational costs by increasing the number of sizes.

\begin{tabular}{|c|c|c|c|c|}
\hline Experiment & E0 & E1 & E2 & E3 \\
\hline$L^{*}$ & 9 & 9 & 9 & 10 \\
\hline$R^{*}$ & 1289080,52 & 1772354,56 & 2062285,20 & 2255524,15 \\
\hline$R_{\bar{L}}^{\bar{L}}$ & 1360835,79 & 1838963,48 & 2125840,09 & 2317091,16 \\
\hline & $15 ; 19 ; 23 ;$ & $15 ; 19 ; 23 ;$ & $15 ; 19 ; 23 ;$ & $15 ; 19 ; 23 ;$ \\
$x_{l_{j}}^{*} \in X^{*}$ & $28 ; 35 ; 46 ;$ & $28 ; 35 ; 45 ;$ & $28 ; 35 ; 45 ;$ & $28 ; 35 ; 45 ;$ \\
& $51 ; 58 ; 65$ & $51 ; 58 ; 65$ & $51 ; 58 ; 65$ & $50 ; 55 ; 58 ;$ \\
& & \multicolumn{4}{|c}{} \\
\hline
\end{tabular}

Table 9. Results from solving the problem with different operational costs

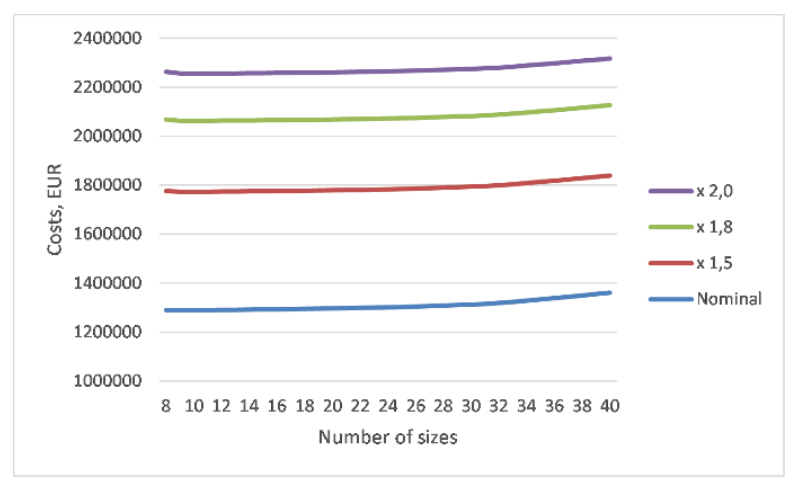

Fig. 11. Change in the total costs for change in the operational costs

\section{Conclusion}

From the research laid out in the current paper the following important results are obtained:

- A mathematical model is proposed of the problem for choosing an optimal size range for a technical product with constraints on the applicability of the elements in the size range.

- Recurrent dependencies are derived for calculating the chosen optimailty criterion.

- The optimal size range for the product "Pipe clamp" is found for predefined application ranges for the elements of the size range.

- A study is made of the influence of the mathematical model's parameters on the optimal solution, and the following is established:

- the mathematical model adequately reflects the conflicting interests of manufacturer and users. Trough it a size range is found, that satisfies all demand with minimum costs. The solution is a compromise between the users' requirement for bigger size range density that satisfies in full their demand, and the manufacturer's requirements for lower density size ranges aiming for bigger batches and lowering the costs for the manufactured products;

- the demand function must be determined with the greatest precision, in order to obtain reliable results;

- increasing the production quantity does not significantly influence the number and values of the sizes in the optimal size range, but decreasing it leads to a decrease in the number of sizes;

- the application range significantly influences the optimal solution;

- the production and operational costs significantly influence the optimum, and must be determined with enough accuracy for obtaining reliable results. 
- The results of the study are valid for a particular product and the particular production and operation conditions. For other type of product it is again necessary to define the corresponding parameters of the mathematical model - demand function, production and operational costs, etc.

- Through the conducted experiments the sensitivity of the elements included in the optimal solution can be studied and analysed regarding changes in the different components of the mathematical model. Even in cases with the same number of elements, different combinations are possible, having close values of their main parameter and with completely or partially overlapping application ranges. This confirms the necessity for post-optimal analysis for studying the optimum and possible close to the optimum solutions.

- Future research will be directed to using method for planning of experiments for the post-optimal analysis and integration of the approach for size ranges optimization in the design of product families.

\section{Acknowledgments}

The authors would like to thank the Research and Development Sector at the Technical University of Sofia for the financial support.

\section{References}

[1] Bellman, R. (2010). Dynamic programming, Princeton University Press, ISBN 978-0-691-14668-3, New York

[2] Borgonovo, E. (2017). Sensitivity analysis, Springer, ISBN 978-3-319-52257-9

[3] Dashenko, A. \& Belousov, A. (1983) Design of automated lines, Visshaia shkola, Moscow

[4] Dichev, D., Zhelezarov, I., Karadzhov, T., Madzharov, N., Diakov, D. (2019) Method of Measuring Motion Parameters of Moving Objects, Environment. Technology. Resources Proceedings of the $12^{\text {th }}$ International Scientific and Practical Conference, Vol. 3, pp. 27-31. ISSN: 1691-5402

[5] Jiao, J., Simpson, T. \& Siddique, Z. (2007). Product family design and platform-based product development: a stateof-the-art review, Journal of Intelligent Manufacturing, Vol. 18, No. 1, (February 2007), pp. 5-29, DOI: $10.1007 / \mathrm{s} 10845-007-0003-2$

[6] Malakov, I. (2015). Optimization of parametric ranges of technical products, In: Complex automation of the discrete production, Malakov, I. \& Nikolov, S., (Eds.), pp. 25-48, TU-Sofia, ISBN 978-619-167-153-3, Sofia

[7] Malakov, I., Zaharinov, V. \& Tzenov, V. (2015). Size ranges optimization, Procedia Engineering, Vol. 100, (January 2015), pp. 791-800, DOI: 10.1016/j.proeng.2015.01.433

[8] Malakov, I. \& Boyadjiev, I. (2001). Choice of optimal range of parameters of technical products, In: Proceedings of the 12th International DAAAM Symposium, Katalinic, B., (Ed.), pp. 285-286, Published by DAAAM International, ISBN 3-901509-19-4, Vienna

[9] Lotz, J. (2018). Beherrschung von Unsicherheit in der Baureihenentwicklung, Ph.D. Dissertation, Mechanical Engineering, TU-Darmstadt, Darmstadt, Germany

[10] Lotz, J., \& Kloberdanz, H. (2014). Scaling under dynamic uncertainty using laws of growth, In: Proceedings of the International Symposium on Robust Design - ISoRD14, Howard, T. \& Eifler, T., (Eds.), pp. 17-27, DOI: 10.4122/dtu:2083, Copenhagen

[11] Lotz, J.; Freund, T., Würtenberger, J. \& Kloberdanz, H. (2016). Uncertainty in Size Range Development - an Analysis of Potential for a new Scaling Approach, International Design Conference - DESIGN 2016, , pp. 341-350, Dubrovnik

[12] Mueller, D. (2011). A cost calculation model for the optimal design of size ranges, Journal of Engineering Design, Vol. 22, No. 7, (July 2011), pp. 467-485, DOI: 10.1080/09544820903449218

[13] Pahl, G., Beitz, W. \& Feldhuzen, J. (2007). Konstruktionslehre. Methoden und anwendung, Springer-Verlag, ISBN 354-0-340-60-2, Berlin/Heidelberg

[14] Rai, R. \& Allada, V. (2003). Modular product family design: agent-based pareto-optimization and quality loss function-based post-optimal analysis, International journal of production research, Vol. 41, No. 17, (November 2003), pp. 4075-4098, DOI: 10.1080/0020754031000149248

[15] Razavi, S. \& Gupta, H. (2016). A new framework for comprehensive, robust, and efficient global sensitivity analysis: Theory, Water Resource Research, Vol. 52, No. 1, (January 2016), pp. 423-439, DOI: 10.1002/2015WR017559

[16] Pianosi, F., Beven, K., Freer, J., Hall, J., Rougier, J., Stephenson, D. \& Wagener, T. (2016). Sensitivity analysis of environmental models: a systematic review with practical workflow, Environmental Modelling \& Software, Vol. 79, (May 2016), pp. 214-232, DOI: 10.1016/j.envsoft.2016.02.008

[17] Saltelli, A., Chan, K., \& Scott, E. (2009). Sensitivity analysis, John Wiley \& Sons, ISBN 978-0-470-74382-9, New York

[18] Simpson, T. (2004). Product platform design and customization: status and promise, Artificial Intelligence for Engineering Design, Analysis and Manufacturing, Vol. 18, No. 1, (February 2004), pp. 3-20, DOI: $10.1017 /$ S0890060404040028

[19] Simpson, T. (2017) Product Family and Product Platform Benchmarking With Commonality and Variety Indices, ASME 2017 International Design Engineering Technical Conferences and Computers and Information in Engineering Conference, DOI: 10.1115/DETC2017-67500 